\title{
Intrarenal Blood Flow Distribution in Canine Puppies
}

\author{
Pedro A. Jose ${ }^{[62]}$, Alexander G. Logan, Lawrence M. Slotkoff, Lawrence S. Lilienfield, \\ Philip L. Galcagno, and Gilbert M. Eisner ${ }^{[61]}$
}

Departments of Pediatrics, Physiology and Biophysics, and Medicine, Georgetown University School of Medicine, Washington, D.C., USA

\begin{abstract}
Extract
The present study was designed to examine the developmental changes in renal blood flow distribution in canine puppies utilizing the techniques of xenon-133 (133Xe) washout, anatomic measurements, and para-aminohippuric acid (PAH) clearances and extractions. The distribution patterns determined by analysis of the xenon washout curves were confirmed by studies of the intrarenal distribution of injected radioactive microspheres. The mean total blood flow was $1.2 \mathrm{ml} / \mathrm{g}$ kidney $/ \mathrm{min}$ at 6 weeks of age and rose progressively to the adult value of $3.5 \mathrm{ml} / \mathrm{g}$ kidney $/ \mathrm{min}$ at $14-16$ weeks of age. The mean Component I flow, $1.7 \mathrm{ml} / \mathrm{g} / \mathrm{min}$ at 6 weeks, increased to $4.7 \mathrm{ml} / \mathrm{g} / \mathrm{min}$ at 14-16 weeks of age. The increase in Component I flow was associated with an increase in PAH extraction ratio. The low renal blood flow observed in the puppy less than 6 weeks of age appears to be due in large part to a small cortical volume. Anatomically, the amount of cortex/medulla ratio was less in the puppy than in the adult, and this was supported by the relatively low cortical volume of distribution noted in the washout studies. At 10 and 12 weeks of age, when the relative cortical mass approximated that found in the adult, the Component I flow rate was still low, but from age 12 weeks, Component I flow and total renal blood flow increased markedly. Renal blood flow increased during a period when cardiac output per kilogram body weight was constant and total peripheral resistance was rising.

The progressive age-dependent increase that was noted in total renal blood flow was primarily due to an increase in cortical flow. The increased cortical flow was in part a consequence of cortical growth; change in sympathetic tone may also have contributed.
\end{abstract}

\section{Speculation}

Alterations in renal blood flow distribution may account for maturational changes in renal excretion of salt and water. Differences in renal blood flow distribution between the puppy and the adult dog may be due in large part to differences in resting vascular tone.

\section{Introduction}

A relatively low blood flow to the kidney cortex in both human and canine neonates has been postulated on the basis of anatomic studies [31] and para-aminohippurate (PAH) extraction ratios $[3,34,38]$. These methods, however, provide only indirect measures of intrarenal blood flow distribution and are too gross to detect small physiologic shifts of flow. The use of PAH extraction as an index of medullary flow [44] is beset by serious flaws since medullary flow may not be the 
sole contributor to renal venous levels of PAH [30, 50]. In the canine, unless rigid precautions are taken during collection, diffusion of $\mathrm{PAH}$ from erythrocytes to plasma may be as high as $15 \%$ within $10 \mathrm{~min}$ [40]. In addition, Thurau [52] has shown that during antidiuresis significant back diffusion of $\mathrm{PAH}$ from the collecting duct into the vasa recta may occur and falsely elevate calculated medullary flows.

Intrarenal blood flow distribution (IRBF) has also been measured by the washout of radioactive noble gases $[28,51]$. This technique, although also imperfect, appears to be reliable for measuring flow distribution to outer regions of the kidney and permits repeated studies in the same animal [28].

Experiments were designed to examine the developmental changes in renal blood flow distribution in canine puppies utilizing the technique of xenon-133 $\left({ }^{133} \mathrm{Xe}\right)$ washout, anatomic measurements, and $\mathrm{PAH}$ clearances and extractions. The distribution patterns determined by analysis of the xenon washout curves were confirmed by studies of the intrarenal distribution of injected radioactive microspheres. Cortical flow was found to increase with age as a result of both an increase in cortical size and an increase in perfusion per gram of tissue. Further, a correlation was noted between increased cortical flow and increased extraction of PAH. These changes were not related to increased cardiac output.

\section{Materials and Methods}

\section{Xenon Washout Studies}

Twenty-five mongrel puppies ranging in age from 6 to 16 weeks and 10 adult mongrel dogs were studied. In 14 of the 25 puppies, a polyethylene catheter (PE 10) was implanted into the left renal artery 2 days prior to the experiment according to the method of Herd and Barger [17]. In the remaining puppies and in the adult dogs, at the time of the study, a 27-gauge butterfly needle was inserted into the right renal artery for xenon injection. The animals were deprived of water and fasted for $12-16 \mathrm{hr}$ prior to the procedure to insure low urine flow [51] and anesthetized with pentobarbital, $30 \mathrm{mg} / \mathrm{kg}$, administered intravenously. Aortic blood pressure was monitored from a catheter inserted through the femoral artery, using a strain gauge transducer [55] connected to a recorder [56].

Renal blood flow distribution was measured by the xenon washout technique [28]; $400-500 \mu \mathrm{Ci}{ }^{133} \mathrm{Xe}$ were dissolved in $0.5 \mathrm{ml}$ saline solution $(0.85 \%)$, injected rapidly into the renal artery, and flushed immediately by an equal volume of the saline. The disappearance of radioactivity was monitored externally by a gamma ray scintillation detector placed over the kidney. The radioactivity was recorded on a linear ratemeter for approximately $15 \mathrm{~min}$. Preliminary studies in our laboratory showed that there was very little difference in values noted for Components I and II when obtained from a 60-min washout curve or when analyzed from the same curve at $15 \mathrm{~min}$. After at least two washout studies, the animal was killed. The kidney was removed and all pelvic structures were cut close to the hilum before weighing. The ${ }^{133} \mathrm{Xe}$ desaturation curve of the kidney was plotted on semilogarithmic paper (Fig. 1). Mean renal blood flow per gram kidney per minute and distribution volumes were calculated according to the method of Carriere et al. [5]. From the washout curve, three to four exponential components were discerned by the peeling-off technique [12]. Since xenon participates in the counter-current mechanism, blood flow measurements for Components III and IV have been questioned [2, 28]. In this study only the two fastest components were used for comparison. Regional flow rates per gram of kidney were calculated from the slopes of each component as described by Thorburn et al. [51]:

$$
F_{1}=\frac{k_{1} \times \lambda \times 1}{P}
$$

where: $F_{1}$ is flow in milliliters per gram of tissue per minute

$\mathrm{k}$ is the slope of each component

$\lambda$ is the partition coefficient for xenon

$\mathrm{P}$ is the specific gravity of the kidney

The partition coefficient for xenon was adjusted according to the hematocrit [28].

Anatomical correlations for the two most rapid flow components in the 6-week-old puppy were determined by autoradiographs of kidneys removed at different time intervals after injection of ${ }^{133 \mathrm{Xe}}$ into the renal artery. The puppies were anesthetized with pentobarbital, and the kidney was exposed retroperitoneally via a flank incision. A 25- or 27-gauge butterfly needle was inserted into the renal artery. Care was taken in dissection to avoid disruption of the renal nerves. A xenon washout curve was done to determine the transit time for the different components. Thirty minutes after the control curve, another injection of radioxenon was given. In one group the kidney was removed $15 \mathrm{sec}$ after the second xenon injection. In the remainder, the kidney was removed 2-4 min after the second injec- 


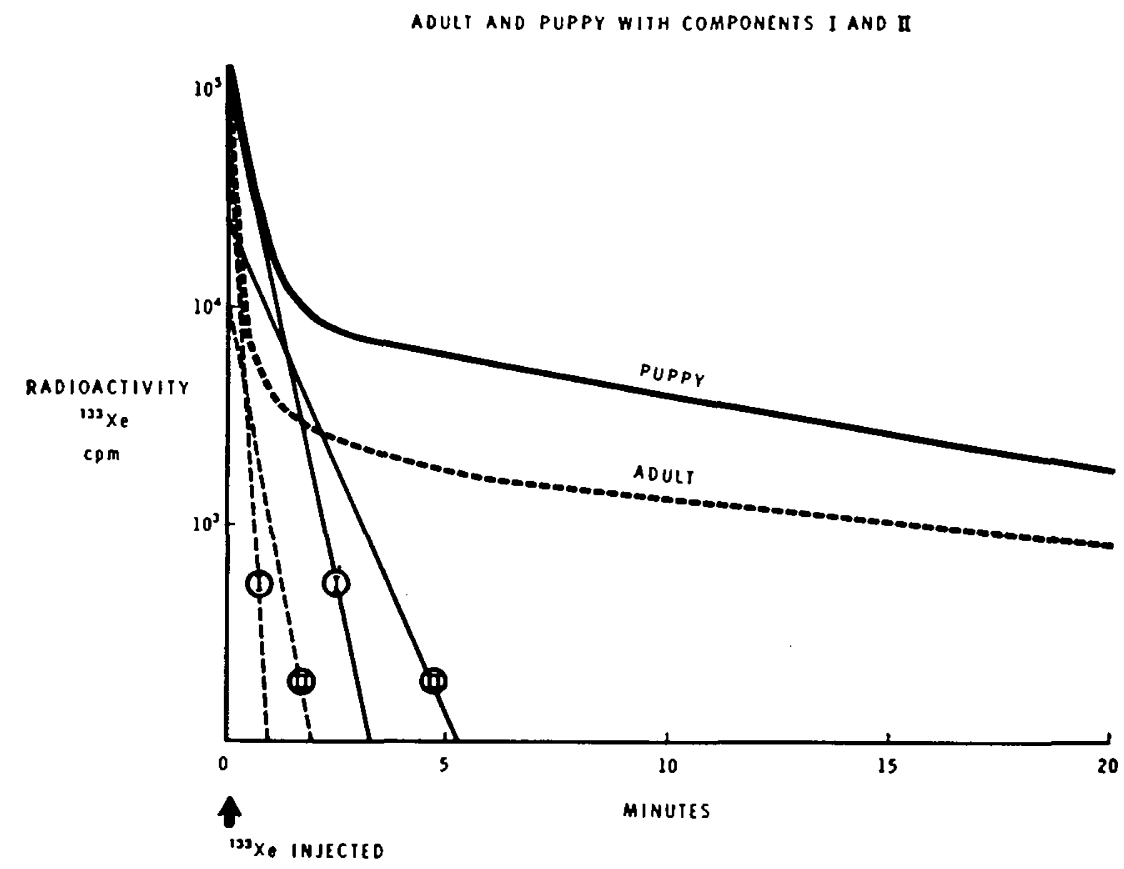

Fig. 1. Xenon-133 washout curves in the 6-week-old puppy and adult dog. During the first 5 min of recording, the tracer disappeared much more slowly in the puppy. Correspondingly, the slopes for Components I and II were slower.

tion, depending upon the transit time for Component I noted in the first xenon injection. Upon removal, the kidney was immediately frozen in a dry ice and acetone mixture.

Coronal sections, $3 \mathrm{~mm}$ in thickness, were sliced from the center of the frozen kidney and exposed to standard x-ray plates. The preparations were stored at $-40^{\circ}$, and the films were developed $1-4$ days later. Following exposure, the kidney slices were examined and measurements were taken of cortical size to delineate the corticomedullary boundary on the autoradiograph.

\section{Chronic Experiments}

Flow distribution in the trained unanesthetized puppy was determined to avoid the complications of trauma and anesthesia [6, 49]. Polyethylene catheters of 0.024 inch external diameter (PE 10) were implanted into the left renal arteries of three puppies at 8 weeks of age. The catheters were flushed daily with 250 units of heparin to prevent clotting. One week was allowed after the operation before studies were undertaken. During this period the puppies were trained to lie quietly on the table for about $20 \mathrm{~min}$. Xenon washout was done every 2 weeks in two puppies up to 15 weeks of age. In the other puppy, studies were done at 10 weeks and 15 weeks of age.

\section{Simultaneous PAH Clearance and Radioxenon Wash- out Studies}

In 12 of the puppies studied by xenon washout, measurements of PAH clearance were made concomitantly. In 2 puppies, 3 weeks of age, $\mathrm{PAH}$ extraction and clearance were done without xenon studies. A 23-gauge butterfly needle was placed into the right renal vein for blood sampling. The right ureter was cannulated by a polyethylene tube, and urine was collected in small graduated cylinders. Para-aminohippurate was administered via a femoral vein to maintain a plasma level of $1-4 \mathrm{mg} / 100 \mathrm{ml}$. An equilibration period of $1 \mathrm{hr}$ was allowed before urine collections were started. Urine was collected every 10-30 min for a total of two to three periods. The blood samples were immediately centrifuged for $5 \mathrm{~min}$ and the plasma was pipetted to another tube. During the collection periods xenon washout curves were determined. After the experiment the kidneys were removed and weighed.

The PAH extraction rate was determined according of the method of Goldring and Chassis [13]. No correction was made for diffusion of $\mathrm{PAH}$ from cells to plasma during collection and centrifugation [40]. Renal plasma flow (RPF) was calculated as clearance of PAH divided by the extraction ratio of PAH (ER). Renal blood flow (RBF) was determined from the for- 
mula $\mathrm{RBF}=\mathrm{RPF} /(\mathrm{l}-0.95 \mathrm{hct})$. The $\mathrm{RBF}$ was divided by the kidney weight and flow expressed in milliliters per gram kidney per minute.

\section{Anatomic Studies}

An index of relative anatomical compartment size was determined in five puppies 4-9 weeks of age. The cortex and medullary widths were measured at the middle of a midcoronal section of the kidney. Results were expressed as cortical/medullary $(\mathrm{C} / \mathrm{M})$ width. The arcuate arteries were used to demarcate the corticomedullary border. Identification of these vessels was facilitated by silicone rubber microcasts.

\section{Microsphere Studies}

To measure flow distribution by another technique and obviate the technical and mathematical problems encountered in the washout analysis [33, 45], IRBF was determined by the microsphere method [48]. Three puppies, 9-10 weeks old, were studied under pentobarbital anesthesia and prepared for xenon injection using the same experimental techniques as were used for the chronic experiment group. One millicurie of ytterbium- 169 labeled microspheres $(15 \pm 5 \mu)$ was uniformly suspended in dextran and Tween 80 by an ultrasonic probe and drawn up into a syringe. The radioactivity in the syringe was determined before and after each injection [33]. Five to eight microcuries were injected into the thoracic aorta. After the animal was killed, the kidney was removed and the capsule stripped; slices were taken from the cortex. The cortical slices were then further divided with the outer two-thirds (outer cortex), separated from the inner one-third (inner cortex). All slices were counted by a gamma ray spectrometer, and flows were expressed in milliliters per gram tissue per minute. Slot- koff and others have demonstrated that the spheres are trapped by the glomeruli (hence there is no recirculation) and that the distribution of the spheres throughout the cortex is not affected by skimming [33, 37, 47, 48]. Therefore, this method can be used as a measure of total renal blood flow and its intracortical distribution. Since the bulk of the medullary blood flow first passes through juxtamedullary glomeruli, where microspheres are trapped, this technique is not a valid indicator of medullary flow.

In all the studies with microspheres and in seven studies in the chronic experiment group, cardiac output was determined by the indocyanine green dilution technique. The dye was injected into the right atrium and blood from the descending aorta was passed through a densitometer [57] at a constant rate of 9 $\mathrm{ml} / \mathrm{min}$. The curve was plotted on semilogarithmic paper, and the cardiac output was calculated according to the method of Lilienfield and Kovach [29]. Flows were expressed in milliliters per kilogram body weight per minute.

The PAH method and xenon washout technique for blood flow determination were compared using the least square method for linear regression. The confidence limits of ratios were established according to the Fieller theorem [14]. The results obtained in the puppies were compared with adult values using Student's $t$ test.

\section{Results}

\section{Anesthetized Dogs}

Xenon washout method. The disappearance curve of xenon observed in a 6-week-old puppy is compared with that found in the adult dog (Fig. 1). During the first $5 \mathrm{~min}$ of recording, the tracer disappeared much

Table I. Summary of renal and distribution flow data ${ }^{1}$

\begin{tabular}{|c|c|c|c|c|c|}
\hline \multirow{2}{*}{ Age, weeks } & \multicolumn{3}{|c|}{ Blood flow, $\mathrm{ml} / \mathrm{g} / \mathrm{min}$} & \multicolumn{2}{|c|}{ Distribution volumes, $\%^{2}$} \\
\hline & Total & Co I & Co II & Co I & Co II \\
\hline $6(5)^{3}$ & $1.2 \pm 0.20^{4}$ & $1.7 \pm 0.12^{4}$ & $0.9 \pm 0.06$ & $52 \pm 1^{5}$ & $48 \pm 1^{5}$ \\
\hline $8-10(10)$ & $1.5 \pm 0.20^{4}$ & $2.0 \pm 0.16^{4}$ & $0.6 \pm 0.13^{6}$ & $62 \pm 3$ & $38 \pm 3$ \\
\hline $10-12(6)$ & $2.2 \pm 0.20^{4}$ & $2.7 \pm 0.17^{4}$ & $1.1 \pm 0.08$ & $64 \pm 4$ & $36 \pm 4$ \\
\hline $14-16(4)$ & $3.5 \pm 0.02$ & $4.7 \pm 0.57$ & $1.1 \pm 0.06$ & $65 \pm 5$ & $35 \pm 5$ \\
\hline Adults (10) & $3.5 \pm 0.23$ & $4.8 \pm 0.3$ & $1.1 \pm 0.14$ & $68 \pm 3$ & $32 \pm 3$ \\
\hline
\end{tabular}

${ }^{1}$ Flow rates and distribution volumes of Components $I$ and II were calculated from xenon-133 washout curves in 25 puppies and 10 adult dogs. Results obtained in the puppies were compared with adult values using Student's $t$ test.

${ }^{2}$ Relative mass of the individual components.

${ }^{3}$ Number in parentheses indicates number of dogs.

${ }^{4} P<0.01$.

$P<0.005$.

${ }^{\circ} P<0.05$. 


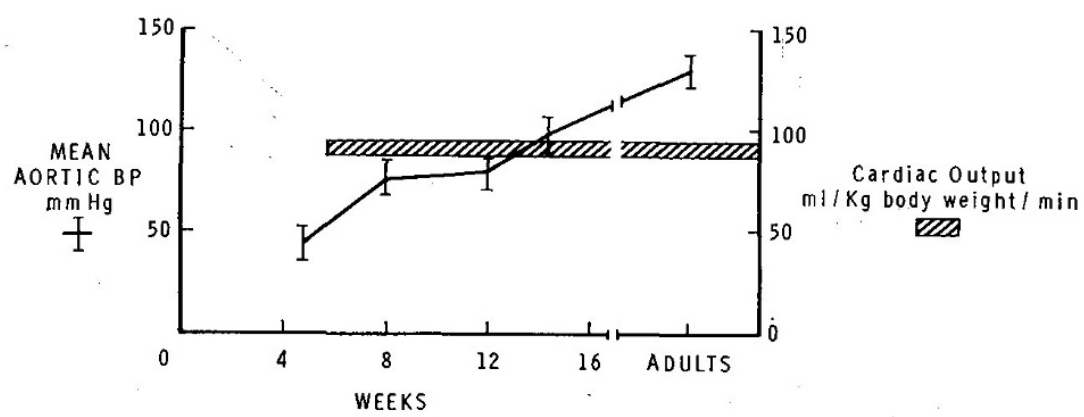

Fig. 2. Mean aortic blood flow rate and cardiac output in puppies of various ages and in adult dogs.

more slowly in the puppy. Correspondingly, the slopes for Components I and II were slower. The results obtained in the 25 puppies and 10 adult dogs are shown in Table I. The mean total flow rate for the puppies was $1.2 \mathrm{ml} / \mathrm{g}$ kidney/min at 6 weeks and rose progressively to the adult value of $3.5 \mathrm{ml} / \mathrm{g}$ kidney $/ \mathrm{min}$ at 14 16 weeks of age. The mean Component I flow rate of 1.7 $\mathrm{ml} / \mathrm{g} / \mathrm{min}$ at 6 weeks increased to $4.7 \mathrm{ml} / \mathrm{g} / \mathrm{min}$ at 14-16 weeks of age. Component I flow rate in the 6- to 12-week-old puppies differed significantly from Component I flow rate in the 14- to 16-week-old puppies and in adults $(P<0.01)$. In contrast, after 10 weeks of age, Component II flow rates were not significantly different from those found in adults. The ratio of Component II flow to Component I flow of $0.53 \pm 0.2$ at 6 weeks of age was significantly different from that obtained in adults, $0.24 \pm 0.03$ [14].

The relative distribution volumes of Component I and Component II are shown in Table I. In the 6week-old puppy, Component I flow accounted for only $54 \%$ of the xenon distribution volume $(P<0.005)$. At 10 weeks of age, however, when the relative volume of Component I flow (64\%) was similar to that obtained in adults (68\%), the Component I flow rate per gram was still relatively low. From age 12 weeks, Component I flow rate and total renal blood flow increased sharply. The cardiac output, however, remained at 90-95 ml $/ \mathrm{kg}$ body weight $/ \mathrm{min}$, a value not significantly different from that obtained in adult dogs (Fig. 2). Mean aortic blood pressure rose slightly during this period $(80 \pm 2.4-100 \pm 2.4 \mathrm{~mm} \mathrm{Hg})$. Thus, renal blood flow increased during a period when cardiac output per kilogram body weight was constant and total peripheral resistance was rising slightly.

Autoradiographs. In autoradiographs of kidneys removed $15 \mathrm{sec}$ after injection of radioxenon, radioactivity was located mainly in the cortex and outer medulla (Fig. $3 \mathrm{~A}$ ). In the experiment shown in Figure 1, at minute 4 of the washout curve, the compartment represented by Component I should have been cleared
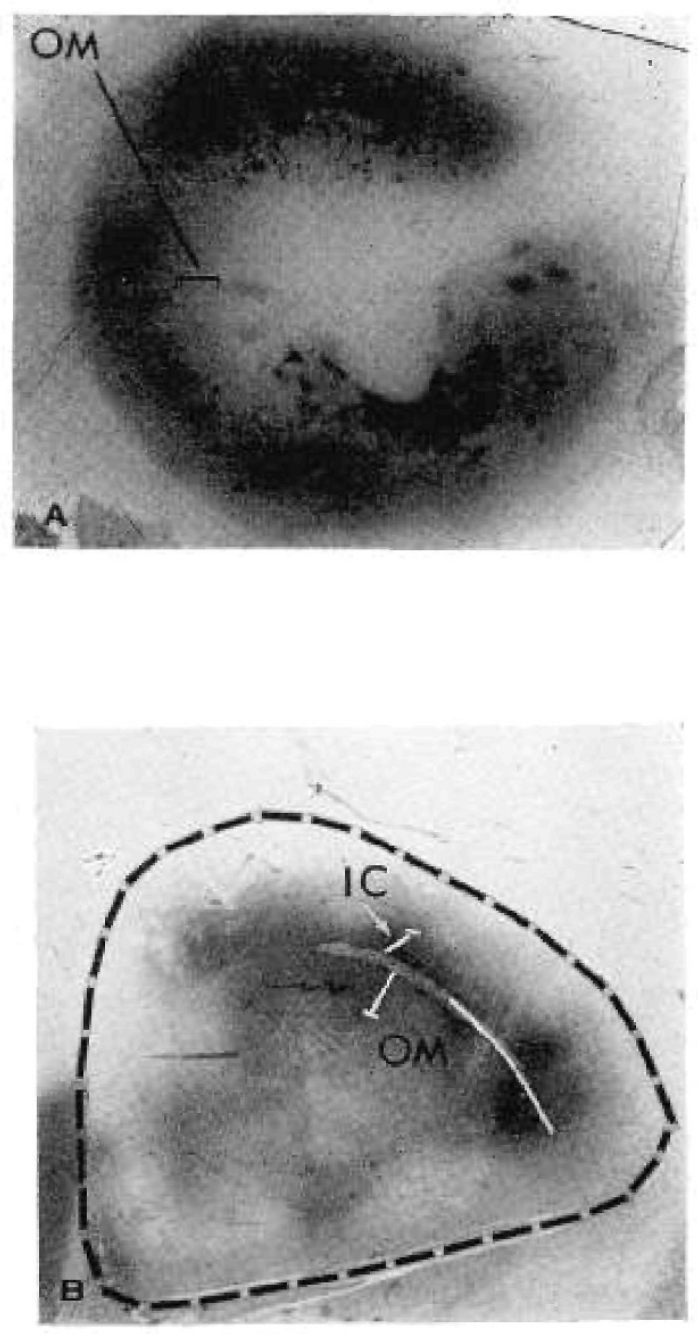

Fig. 3. A. Autoradiograph of a midcoronal section of the kidney $15 \mathrm{sec}$ after the second intrarenal injection of ${ }^{133} \mathrm{Xe}$. Radioactivity is located throughout the cortex and outer medulla (OM). The kidney was obtained from a 6-week-old puppy. $B$. Autoradiograph of a midcoronal section of the kidney 4 min after the second intrarenal injection of ${ }^{133} \mathrm{Xe}$. Radioactivity is located mainly in the inner cortex (IC) and outer medulla (OM), indicating that in the 6-week-old puppy, Component I represents outer cortical flow. Solid line represents the corticomedullary junction. 


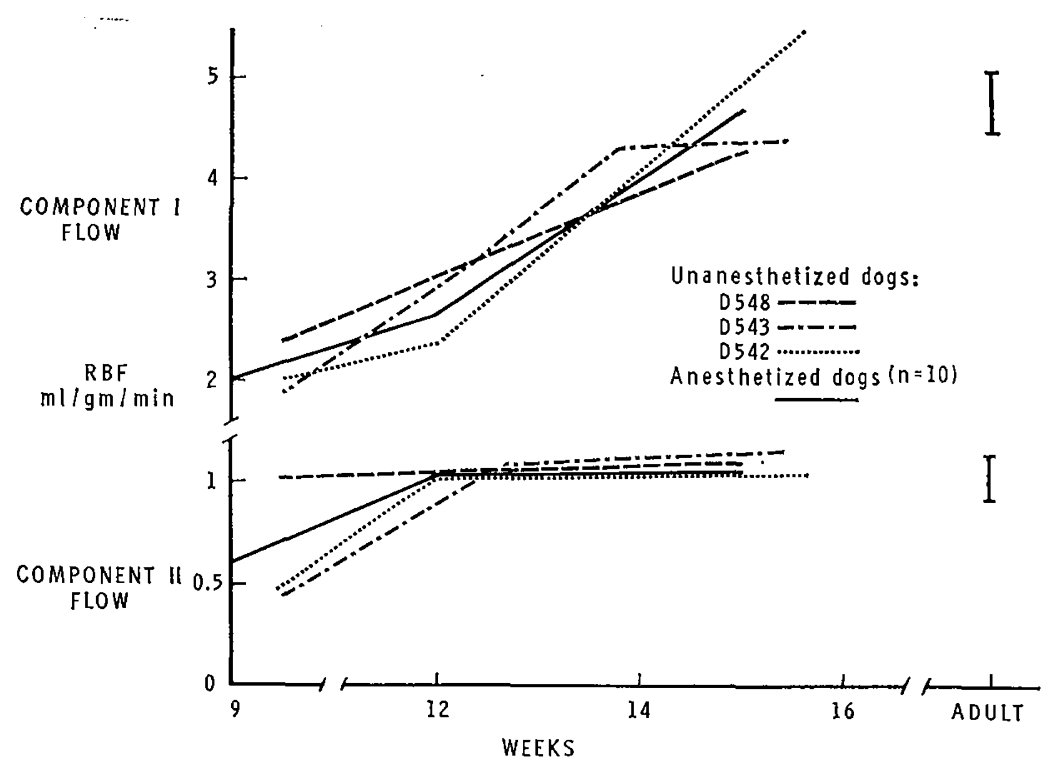

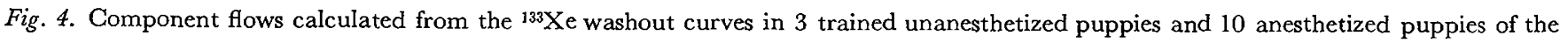
same age group.

of radioactivity while significant radioactivity remained in the compartment represented by Component II. The autoradiograph showed that radioactivity at that time was confined to the inner cortex and outer medulla (Fig. $3 \mathrm{~B}$ ). Similar results were obtained consistently in the studies done on the 6-week-old puppies. Therefore, it appears that Component I flow in the young puppy represents outer cortical flow while the Component II flow represents flow to the inner cortex and outer medulla. At 14 weeks of age the pattern resembled that found in adults; i.e., 2 min after injec-

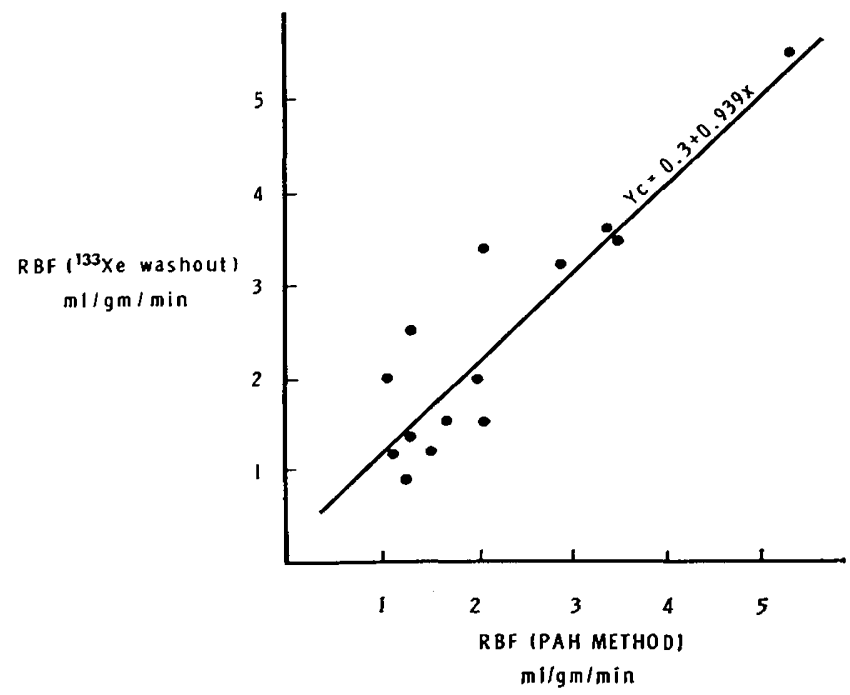

Fig. 5. Comparison of the ${ }^{133} \mathrm{Xe}$ washout method and the PAH extraction technique of determining total renal blood flow. tion radioactivity was confined mainly to the outer medulla.

\section{Unanesthetized Dogs}

The xenon washout curves in unanesthetized puppies were very similar to those obtained in anesthetized puppies at the same age (Fig. 4). There was a progressive increase in Component I flow from 2.1 $\mathrm{ml} / \mathrm{g} / \mathrm{min}$ at 9 weeks to $4.7 \mathrm{ml} / \mathrm{g} / \mathrm{min}$ at $14-16$ weeks of age. Component II flow rose and stabilized at adult values of $1.1 \mathrm{ml} / \mathrm{g} / \mathrm{min}$ after 12 weeks.

\section{Comparison between PAH Method and Xenon Wash out}

The mean renal blood flow determined from the xenon washout method was compared with results obtained by the PAH technique (Fig. 5). The correlation was excellent with a correlation coefficient of 0.89 .

$P A H$ extraction. The $\mathrm{PAH}$ extraction ratios rose progressively from 0.44 at 6 weeks to 0.75 at 12-14 weeks of age. Only those levels in puppies younger than 12 weeks were significantly different from those observed in older dogs including adults $(P<0.05)$. The increase in PAH extraction was consonant with the increase in Component I flow (Fig. 6).

\section{Silicone Rubber Microcasts}

The relative anatomic size of the compartments as indicated by the ratio cortex width to medullary width $(\mathrm{C} / \mathrm{M})$ was $0.20,0.28$, and 0.32 at 4,7 , and 9 weeks, 


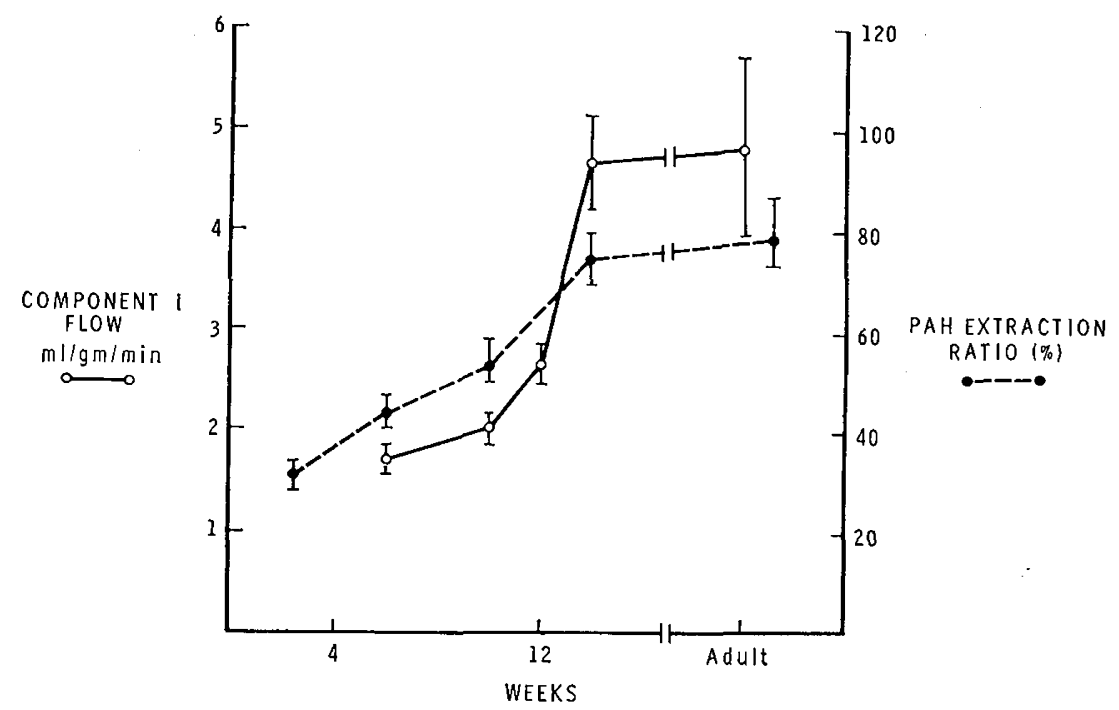

Fig. 6. Changes in PAH extraction ratios and Component I flow associated with age.

respectively. The increase in $\mathrm{C} / \mathrm{M}$ at 9 weeks was significant at $P<0.05$.

\section{Microsphere Method}

The results of the microsphere studies compared with those from the simultaneous xenon washout studies in the three puppies and five adult dogs are shown in Table II. In the three puppies the mean renal blood flow measured with microspheres was $1.3 \mathrm{ml} / \mathrm{g} /$ min while a value of $1.4 \mathrm{ml} / \mathrm{g} / \mathrm{min}$ was obtained by the xenon washout technique in two of the three animals. (In 10 additional studies at 10 weeks of age, using xenon washout [Table I], the mean flow was 1.5 $\mathrm{ml} / \mathrm{g} / \mathrm{min}$.) The Component I flow rate of $1.9 \mathrm{ml} / \mathrm{g} /$ min using the xenon washout procedure was similar to that of the outer cortical flow of $2.09 \mathrm{ml} / \mathrm{g} / \mathrm{min}$ obtained using microspheres. Furthermore, when compared with adult values obtained in a separate study from this laboratory [33], the blood flow to the cortex in the puppy was significantly lower, confirming the findings of the washout technique $(P<0.01)$.

\section{Discussion}

Both the xenon washout and the microsphere studies demonstrate for the first time the previously postulated low cortical blood flow in the kidney of the young canine. Maturation was associated with a rise in total renal blood flow due primarily to increased cortical flow. The low renal blood flow in the puppy under 6 weeks of age appears to be due in large part to a small cortical volume. Anatomically, the amount of cortex compared with medulla is less than that found in the adult and this is supported by the relatively low volume of distribution noted in the washout studies. At 10 and 12 weeks, when the relative cortical mass (as indicated by the distribution volume of Component I

Table II. Comparison of the xenon-133 washout method and the microsphere technique for determination of renal blood flow

\begin{tabular}{|c|c|c|c|c|c|c|c|c|c|}
\hline \multirow{3}{*}{ Age, weeks } & \multirow{3}{*}{$\mathrm{Wt}, \mathrm{kg}$} & \multirow{3}{*}{$\begin{array}{l}\text { Cardiac } \\
\text { output, } \\
\mathrm{ml} / \mathrm{min}\end{array}$} & \multicolumn{7}{|c|}{ Flow, $\mathrm{ml} / \mathrm{g} / \mathrm{min}$} \\
\hline & & & \multicolumn{3}{|c|}{ Xenon washout } & \multicolumn{4}{|c|}{ Microsphere } \\
\hline & & & Total & $\mathrm{CoI}^{1}$ & Co II 1 & Total & Cortex & $\mathrm{OC}^{2}$ & $\mathrm{IC}^{2}$ \\
\hline 10 & 5 & 479 & 1.5 & 2.2 & 0.8 & 1.44 & 1.57 & 2.08 & 0.84 \\
\hline 9 & 5.4 & 455 & 1.3 & 1.6 & 0.4 & 1.10 & 1.45 & 1.60 & 0.76 \\
\hline 10 & 5 & 466 & $\mathrm{ND}^{3}$ & ND & ND & 1.43 & 1.7 & 2.61 & 1.34 \\
\hline Mean, puppy & 5.1 & 467 & 1.4 & 1.9 & 0.6 & 1.32 & 1.57 & 2.09 & 0.98 \\
\hline Mean, adult ${ }^{4}(5)^{6}$ & 18 & 1,700 & 3.5 & 4.8 & 1.1 & 3.20 & 5.32 & 6.72 & 3.23 \\
\hline
\end{tabular}

1 Components I and II.

2 OC: outer cortex; IC: inner cortex.

${ }^{3} \mathrm{ND}$ : not done.

${ }^{4}$ Logan et al. (33), to be published.

"Number in parentheses indicates number of animals. 
flow and by anatomic studies) approximates that in the adult, the Component I flow rate was still low. From 12 weeks of age on, however, Component I flow and total renal blood flow increased markedly. A similar progressive increase in total renal blood flow with age has also been shown by Horster [21]. Using the piglet Gruskin et al. [16] demonstrated that the increase in renal blood flow in the first 6 weeks of life was due to an increase in cardiac output as well as to a decrease in renal vascular resistance; beyond 6 weeks of age the increase in renal blood flow is probably due solely to a decrease in renal vascular resistance. In the pig, glomerulogenesis continues after birth and may well play a part in the increased perfusion. In the dog, however, the increase in renal blood flow cannot be ascribed to formation of new glomeruli since in this species, as in man, no new glomeruli are formed after birth [42]. In the present study, the cardiac output remained at $90-95 \mathrm{ml} / \mathrm{kg}$ body weight $/ \mathrm{min}$ from 7 weeks of life on, a value not significantly different from that obtained in anesthetized adult dogs. Mean blood pressure rose slightly with age. Thus, renal blood flow increased during a period when cardiac output per kilogram body weight was constant and total peripheral resistance was rising.

In man, it has been demonstrated anatomically that after birth there is a progressive dilatation of the vessels in organs throughout the body, with the renal vessels showing a greater increase than vessels in the other organs studied [25, 39]. Although this finding might explain in part the increase in total renal blood flow noted with maturation, it does not explain the change in distribution of blood flow observed in the present study. The role of the sympathetic nervous system in the high renal resistance of the neonate has not been fully examined. The demonstration of adrenergic innervation of afferent and efferent arterioles in the kidney $[32,36]$ and the redistribution of blood flow following carotid and splanchnic stimulation [41] indicate that neural discharge or tone may be a significant factor in determining flow distribution in adult dogs. Gill [11] recently reported that the $\beta$-adrenergic agent, isoproterenol, increased urine flow and fractional sodium excretion in the kidney when $\alpha$ receptors were blocked by dibenzyline. Studies in 7- to 10 week-old puppies have demonstrated that administration of isoproterenol into the renal artery resulted in an increase in Component I flow [26], suggesting that prior to isoproterenol administration significant tonic vascular activity existed in the puppy kidney. Anesthesia was probably not a significant factor since similar flow patterns were obtained in the control, trained unanesthetized puppies included in this report.

Since the studies of Calcagno and Rubin [3] were reported, demonstrating the low PAH extraction in human infants, several investigators have found similarly low ERs in other species [21, 22, 34, 38]. Our studies support these findings. Differences in absolute values may be due to technique [40] or hematocrit [27]. Nonetheless, the values in our studies were lower than adult values and approximated them only after 12-16 weeks of age. Rennick et al. [43] and more recently Hook et al. [20] found that in vitro, the PAH transport ability of the puppy kidney after 2 weeks of life was similar to that of adults. Therefore, the increase in PAH extraction associated with age may be taken as further evidence of redistribution in blood flow from the juxtamedullary area to the outer cortex. In fact, when cortical flow is increased in the young puppy by isoproterenol administration, the PAH extraction ratio rises concomitantly [26].

Micropuncture studies [24,53] in the rat have demonstrated higher rates of glomerular filtration (GFR) in juxtamedullary nephrons than in superficial cortical nephrons. Jamison [24] has suggested that the higher GFR in the juxtamedullary nephrons is probably due to both a larger filtering surface and a higher filtration pressure. In humans, however, although the neonatal glomerulus is relatively larger than the adult glomerulus, GFR is disproportionately low $[9,54]$. If the high filtration fraction previously reported in infants is correct [46], redistribution of blood flow from the juxtamedullary to the outer cortical regions (higher renal blood flow and lower GFR) could account in part for the decrease in filtration fraction observed with age. That the filtration fraction in puppies may not in fact be unusually high has been reported recently. Horster [21] and Horster and Lewy [22] found in young rats and in puppies that filtration fraction increased with age. Increase in GFR per se may be due to increase in blood pressure [34], a change in efferent-afferent arteriolar tone, or an increase in glomerular permeability [15].

Studies in man and other experimental animals have shown that a decrease in cortical flow was associated with increased sodium reabsorption while, in situations of increased cortical flow, sodium diuresis occurs $[2,4,18,19,37]$. In the rat and in the dog saline infusion has been shown to increase filtration rate in superficial nephrons and increase fractional sodium excretion [1, 23, 53]. In studies in neonates [35], human infants and piglets fed salted milk and water devel- 
oped edema, and sodium and chloride concentrations in serum increased. When salt was then restricted, weight loss occurred accompanied by a decrease in sodium concentrations. The present finding of relatively low cortical and high juxtamedullary flows in the young puppy is in keeping with the suggestion that juxtamedullary nephrons may be largely responsible for neonatal filtration [31]. It is not surprising, therefore, that puppies can conserve sodium in the presence of salt deprivation [10] since a large portion of the filtrate is probably presented to nephrons with longer loops which may well have a greater capacity for sodium reabsorption [53].

\section{Summary}

Intrarenal blood flow distribution was measured in 28 puppies using the xenon washout method. This technique was compared with the microsphere method in three puppies. In three other puppies, studies were done in the unanesthetized state. A progressive increase in total renal blood flow was noted with age primarily owing to an increase in cortical flow. The increased cortical flow was in part a consequence of cortical growth; change in sympathetic tone may also be a contributing factor.

\section{Addendum}

Recently Horster et al. have demonstrated that in the canine, glomerulogenesis may continue for the first 3 weeks of life, but not beyond. (Horster, M., Kemler, B. J., and Valtin, H.: Intracortical distribution of number and volume of glomeruli during postnatal development in the dog. J. Clin. Invest., 50:796 (1971).)

\section{References and Notes}

1. Auld, R. B., Alexander, E. A., And Levinsky, N. G.: Nephron filtration and proximal reabsorption during saline infusion, arterial clamping and hemorrhage in the dog (Abstract). Annual Meeting of Society for Clinical Investigation, Atlantic City, N.J., p. 5a (1970).

2. BARGER, A. C.: Renal hemodynamic factors in congestive heart failure. Ann. N. Y. Acad. Sci., 139: 276 (1966).

3. Calcagno, P. L., And Rubin, M. I.: Renal extraction of paraminohippurate in infants and children. J. Clin. Invest., 42: 1632 (1963).

4. Carriere, S., and Friborg, J.: Intrarenal blood flow and PAH extraction during angiotensin infusion. Amer. J. Physiol., 217: 1708 (1969).

5. Carriere, S., Thorburn, G. D., O'Morchoe, C. C. C., and BARGER, A. C.: Intrarenal distribution of blood flow in dogs during hemorrhagic hypotension. Circ. Res., 19: 167 (1966).

6. Dawes, G. S.: Foetal and Neonatal Physiology, p. 184 (Yearbook Medical Publishers, Chicago, 1968).
7. Dean, R. F. A., ANd McCance, R. A.: The renal response of infants and adults to the administration of hypertonic solutions of sodium chloride and urea. J. Physiol., 109: 81 (1949).

8. Edelman, C. M., JR.: Maturation of the neonatal kidney. Proceedings of 3rd International Congress of Nephrology, Washington, D.C., Vol. 3, p. 1 (1966).

9. Fetrerman, G. H., Shiplock, N. A., Philip, F. J., and Gregg, $H$. S.: The growth and maturation of human glomeruli and proximal convolutions from term to adulthood. Studies by microdissection. Pediatrics, 35: 601 (1965).

10. Fine, B. P., Satrasook, S. S., and Edelman, C. M., JR.: Renal response of puppies to sodium deprivation (Abstract). 39th Annual Meeting of Society for Pediatric Research, Atlantic City, N.J., p. 115 (1969).

11. Gill, J. R., JR., And Casper, A. G.: Depression of proximal tubular sodium reabsorption by beta adrenergic stimulation (Abstract). Annual Meeting of Society for Clinical Investigation, Atlantic City, N.J., p. 34a (1970).

12. Glicksman, A. M., and Ruderman, H. D.: Fundamentals for Advanced Mathematics, p. 453 (Holt, Rinehart and Winston, New York, 1964).

13. Goldring, W., and Chasis, H.: Hypertension and Hypertensive Disease. (Commonwealth Fund, New York, 1944).

14. Goldstein, A.: Biostatistics. An Introductory Text, p. 185 (Macmillan Company, New York, 1964).

15. Grotre, G., Arturrson, G., And Malmberg, P.: Maturation of kidney function. Proceedings of 12th International Congress on Pediatrics, Mexico City, Vol. 3, p. 32 (1968).

16. Gruskin, A. B., Edelman, C. M., JR., ANd Yuan, S.: Maturational changes in renal blood flow in piglets. Pediat. Res., 4: 7 (1970).

17. Herd, J. A., and Barger, A. C.: Simplified technique for chronic catheterization of blood vessels. J. Appl. Physiol., 19: 791 (1964).

18. Hollenberg, N. K., Epstein, M., Gutmman, R. D., Carray, M., BASCH, R. I., AND MERILL, J. P.: Effect of sodium balance on intrarenal distribution of blood flow in normal man. J. Appl. Physiol., 28: 312 (1970).

19. Hollenberg, N. K., Epstein, M., Rosen, S. M., Basch, R. I., OKEN, D. E., AND MERILL, J. P.: Acute oliguric renal failure in man. Evidence for preferential renal cortical ischemia. Medicine, 47: 455 (1968).

20. Hook, J. B., Williamson, H. C., and Hirsch, G. H.: Functional maturation of renal PAH transport in the dog. Can. J. Physiol. Pharmacol., 48: 169 (1970).

21. Horster, M.: Postnatal fluid reabsorption in single nephrons of the dog kidney (Abstract). Annual Meeting of Society for Clinical Investigation, Atlantic City, N.J., p. 45a (1970).

22. Horster, M., AND LEWX, J. E.: Influence of maturation on GFR and RBF in the rat kidney (Abstract). 39th Annual Meeting of Society for Pediatric Research, Atlantic City, N.J., p. 117 (1969).

23. JAMISON, R. L.: Effect of saline infusion on filtration rate and sodium reabsorption in single superficial and juxtamedullary nephrons (Abstract). Annual Meeting of Society for Clinical Investigation, Atlantic City, N.J., p. 19a (1970).

24. Jamison, R. L.: Micropuncture study of superficial and juxtamedullary nephrons in the rat. Amer. J. Physiol., 218: 46 (1970).

25. JAYKA, S.: The problem of dormant foetal organs, the kidneys, lungs and gut. Biol. Neonat., 3: 343 (1961). 
26. Jose, P. A., Slotkoff, L. M., Lilienfield, L. S., Calcagno, P. A., AND EISNER, G. M.: Intrarenal blood flow distribution in canine puppies (Abstract). Clin. Res., 28: 504 (1970).

27. KinTeR, W. B., AND PAPpenheimer, J. R.: Renal extraction of PAH and diodrast ${ }^{181}$ as a function of arterial red cell concentration. Amer. J. Physiol., 185: 391 (1956).

28. LADEFOGED, J.: Measurements of the renal blood flow in man with the ${ }^{138}$ xenon washout technique. Scand. J. Clin. Lab. Invest., 18: 299 (1966).

29. Lilienfield, L. S., and Kovach, R. D.: Simplified method for calculating flow, mean circulation time and downslope from indicator dilution curves. Proc. Soc. Exp. Biol Med., 91: 595 (1956).

30. Lilienfield, L. S., ANd Maganzini, H. C.: Regulation of medullary flood flow. Compt. Renal Congr. Intern. Nephrol. Geneva, Evioni 1st, p. 562 (1961).

31. LJUNDQvist, A.: Foetal and postnatal development of intrarenal pattern in man. Acta Pediat., 52: 443 (1963).

32. LJundevist, A., AND WAgermark, J.: The adrenergic innervation of intrarenal glomeruli and extra-glomerular circulatory routes. Nephron, 7: 218 (1970).

33. Logan, A. G., Jose, P., Eisner, G. M., Lilienfield, L. S., ANd SLOTKOFF, L. M.: Intrarenal distribution of blood flow in shock. To be published.

34. Lubbe, R. J., and Kleinman, L. I.: Renal function in newborn puppies (Abstract). 39th Annual Meeting of Society for Pediatric Research, Atlantic City, N.J., p. 119 (1969).

35. McCance, R. A., ANd Widdowson, E. M.: Hypertonic expansion of extracellular fluids. Acta Paediat., 46: 337 (1957).

36. McKenna, O. C., and Angelakas, E. T.: Adrenergic innervation of the canine kidney. Circ. Res., 22: 345 (1968).

37. MCNAY, J. L., AND ABE, Y.: Effects of acute and chronic salt loading on the distribution of renal cortical blood flow (Abstract). Clin. Res., 28: 510 (1970).

38. Moore, E. S., Satrasook, S. S., Fine, B. P., Katz, M. C., and Edelman, C. M., JR.: PAH extraction in puppies (Abstract). 39th Annual Meeting of Society for Pediatric Research, Atlantic City, N.J., p. 119 (1969).

39. NAEYE, R. L.: Development of systemic and pulmonary arteries from birth through early childhood. Biol. Neonat., 10: 8 (1966).

40. Phillips, R. A., Dale, V. P., Hamilton, P. B., Emerson, K., JR., Archebald, R. M., Van Slyke, D. D., Stanley, E. G., and BECKER, W. H.: Effects of hemorrhage and traumatic shock on renal function of dogs. Amer. J. Physiol., 145: 314 (1946).

42. Potter, E. L., AND ThIerstein, S. T.: Glomerular development in the kidney as an index of foetal maturity. J. Pediat., 22: 695 (1943).

43. Rennick, B., Hamilton, B., and Evans, R.: Development of renal tubular transport of TEA and PAH in the puppy and piglet. Amer. J. Physiol., 201: 743 (1961).
44. Reubi, R. C.: Objectiones a la theorie de la separation intrarenale des hematies et du plasma. Helv. Med. Acta, 25: 516 (1958).

45. Riggs, D. S. Mathematical Approach to Physiological Problems. A Critical Approach. (Williams and Wilkins, Baltimore, 1963).

46. RUBIN, M. I., BROCK, E., AND RAPAPORT, M.: Maturation of renal function in childhood: Clearance studies. J. Clin. Invest., 28: 1114 (1949).

47. Rudolph, A. M., and Heyman, M. A.: The circulation of the fetus in utero. Circ. Res., 21: 163 (1967).

48. Slotkoff, L. M., D'Avella, J., Eisner, G. M., ANd LilienFIELD, L. S.: Intrarenal blood flow distribution by microsphere method (Abstract). 3rd Annual Meeting American Society of Nephrology, Washington, D.C., p. 62 (1969).

49. Smith, H. G.: The Kidney, Structure and Function in Health and Disease, p. 414 (Oxford University Press, New York, 1951).

50. Tanner, G. A.: Micropuncture studies of PAH and diodrast transport in necturus kidney. Amer. J. Physiol., 212: 134l (1967).

51. Thorburn, G. D., Kopald, H. H., Herd, J. A., Hollenberg, M., O'Morchoe, C. C., AND BARGER, A. C.: Intrarenal distribution of nutrient flow determined with $\mathrm{Kr}^{85}$ in the unanesthetized dog. Circ. Res., 13: 290 (1963).

52. Thurau, K.: Renal hemodynamics. Amer. J. Med., 36: 698 (1964).

53. Thurau, K., AND Horster, M.: Micropuncture studies on filtration rate of single superficial and juxtamedullary glomeruli in rat kidney. Arch. Ges. Physiol., 301: 162 (1968).

54. Zolnai, B., and Palkowitz, M.: Glomerulometrics. Acta Biol. Acad. Sci. Hung., 15: 393 (1965).

55. Statham Instruments, Oxnard, Calif.

56. Sanborn Co., Waltham, Mass.

57. Gilford Instrument Labs, Oberlin, $O$.

58. The authors wish to thank Dr. Gerald Hogan for his surgical assistance, Mrs. Ellen Costello for her secretarial assistance, and Mrs. Jean Young and Mrs. Mary Wypych for their technical help.

59. Presented in part at the 40th Annual Meeting, Society for Pediatric Research, Atlantic City, N.J., May 2, 1970, and The American Federation for Clinical Research, Eastern Section, Washington, D.C., December 13, 1969.

60. Supported in part by Public Health Services Research Grants nos. HE 5353, HE 5527, and HE 12827 and by a Washington Heart Association grant to Dr. Gilbert Eisner.

61. Department of Medicine, Georgetown University Hospital, Washington, D.C.

62. Requests for reprints should be addressed to: Pedro A. Jose, M.D., Department of Pediatrics, Georgetown University School of Medicine, Washington, D.C. 20007 (USA).

63. Accepted for publication, October 8, 1970. 